\title{
Use of "Micro"-Corridors by Eastern Coyotes, Canis latrans, in a Heavily Urbanized Area: Implications for Ecosystem Management
}

\author{
JONATHAN G. WAY ${ }^{1}$ and DAVID L. EATOUGH ${ }^{2}$ \\ ${ }^{1}$ Biology Department, Boston College, Higgins Hall, Chestnut Hill, Massachusetts 02467 USA. e-mail: jw9802@yahoo.com. \\ Present address: 64 Cranberry Ridge Road, Marstons Mills, Massachusetts 02648 USA. \\ ${ }^{2}$ Science Department, Revere High School, 101 School Street, Revere, Massachusetts 02151 USA
}

Way, Jonathan G., and David L. Eatough. 2006. Use of "micro"-corridors by eastern Coyotes, Canis latrans, in a heavily urbanized area: implications for ecosystem management. Canadian Field-Naturalist 120(4): 474-476.

We document the use of very narrow, linear corridors (termed "micro-corridors") that facilitated movements by both a transient and a resident group of eastern Coyotes (Canis latrans) in a heavily urbanized area in north Boston, Massachusetts. Two corridors are discussed: one, a railroad line through downtown Boston; and two, a hole in a cemetery fence giving access to two separated cemeteries in a region of intense human development. Coyotes can be good subjects to illustrate the use of fragmented landscapes because they are common and thus are abundant enough to study yet are wary and avoid novel things and generally avoid people.

Key Words: Eastern Coyote, Canis latrans, corridor, fragmentation, Massachusetts, micro-corridor, urbanization.

The use of corridors is becoming increasingly recognized as an important conservation tool in fragmented landscapes (Beier 1995; Gilbert et al. 1998; Meffe and Carroll 1994). Corridors are strips of habitat connecting otherwise isolated habitat patches and have been promoted as important features of reserve design that allow movement among high(er) quality habitats (Meffe and Carroll 1994). Connecting landscapes rather than maintaining a large unfragmented core ecosystem is becoming the only alternative in many urbanized areas, especially where unregulated sprawl is occurring (e.g., Beier 1995). Yet, there is a paucity of data on animal use of corridors and how effective they are in connecting landscapes (Gilbert et al. 1998; Meffe and Carroll 1994). Because of the natural history of predators (e.g., large territories, longdistance movements), a knowledge of carnivore biology can predict minimum areas where ecosystems can function relatively naturally (Beier 1993; Gittleman et al. 2001; Mech and Boitani 2003; Meffe and Carroll 1994; Way et al. 2002a). However, the effectiveness (positive or negative) of corridors could greatly affect the size needed to maintain predators in certain sized refuges.

Coyotes are common in North America (Parker 1995), yet are elusive and difficult to capture (Way et al. 2002b); they are known to avoid novel objects and structures that are dangerous to them, such as box traps (Way et al. 2002b) or foothold traps (Conner et al. 1998; Sacks et al. 1999). Because Coyotes are ubiquitous (Parker 1995), neophobic and wary (Sequin et al. 2003), and have relatively large home ranges and movement rates (Way et al. 2004), they are a good species to use in the determination of corridor use, especially in urban areas. In other words, although they are common and frequently use human-dominated areas (Grinder and Krausman 2001; Way et al. 2004), they are naturally shy and avoid people by being nocturnal and traveling quickly in and out of human-dominated areas. For example, Way et al. (2004) found that Coyotes travel extensive distances on linear pathways such as powerlines, railroad tracks and golf courses in urbanized areas of Cape Cod, Massachusetts. Findings of Coyote use of corridors in highly urbanized and fragmented areas can potentially be used by managers to help protect more rare species and/or better design reserves for more common species. In this note, we describe the use of very narrow, linear (also called line corridors by Meffe and Carroll 1994) "micro"-corridors.

\section{Study Area and Methods}

Coyotes were captured for an ecological study on the north edge of Boston $\left(42.43^{\circ} \mathrm{N}, 71.06^{\circ} \mathrm{W}\right)$, in eastern Massachusetts, in the bordering cities of Everett (4345.0 people $/ \mathrm{km}^{2}$ ), Malden (4290.5 people $/ \mathrm{km}^{2}$ ), and Revere (3089.0 people $/ \mathrm{km}^{2}$ ) (U.S. Census Bureau, 2000 estimates). Coyotes were captured by box trap (Way et al. 2002a) or by ground-based netlauncher (one coyote; Coda Enterprises, Mesa, Arizona) and outfitted with radio-collars (Mod-400, Telonics, Mesa, Arizona, USA and M1900, Advanced Telemetry Systems, Isanti, Minnesota, USA). Tracking protocols were described by Way et al. (2002a) and Way et al. (2004). Portable receivers (Custom Electronics, Urbana, Illinois, USA) and hand-held 3-element Yagi antennas were used to radio-track Coyotes both on foot and from a vehicle. Because of the highly developed landscape with many roads we mostly restricted our activities to automobiles as Coyotes did not react to them as much as to people (e.g., by running away; J. Way, unpublished data); occasionally we approached radio-collared Coyotes as close as possible on foot without disturbing them. We used binoculars and video-cameras when observing Coyotes, and city street lights, nightscopes, and occasionally headlights when following Coyotes at night with a vehicle (Way et al. 2002a; Way et al. 2004). 


\section{Observations}

On 13 April 2004 we box-trap captured a dispersing $13.6 \mathrm{~kg}$ female Coyote ("Fog" - ID \#BN0402) in a wooded section of Revere. Based on her behavior, she seemed to have been dispersing from the north to the south when she reached our study area. Her movements the week after capture were mostly to the south, including traveling $>1 \mathrm{~km}$ through densely populated neighborhoods and streets. She localized in four different areas for 2-3 days each before moving to a new location. On 26 April 2004 we located her in a fencedin abandoned field of ca. 4 ha behind a shopping mall at the north edge of the city limits of Boston. She reached that location by either swimming a $200 \mathrm{~m}$ river or traveling along railroad tracks over that same river. Based on data taken earlier that night we suspect that she went on the railroad tracks. For 3 days she remained in the fenced-in area and ate many Norway Rats (Rattus norvegicus) and Cottontail Rabbits (Sylvilagus floridanus) (J. Way, unpublished data).

On the night of 29 April she traveled $1.8 \mathrm{~km}$ southwest on the railroad line (which was bordered by industrial buildings on both sides), going under Interstate 93 and the Zakim Bridge, and entered an abandoned railroad yard in Boston where she spent the following day in a sparsely vegetated $200 \times 50 \mathrm{~m}$ area. At 02:00 $\mathrm{h}$ on 30 April she followed the railroad tracks west through the Cambridge part of Boston and found the first wooded area available $4.9 \mathrm{~km}$ from her previous day's location. She was inactive through $23: 37 \mathrm{~h}$ on 30 April 2004 and could not be located until 19 November 2004 when she was found alive $100.5 \mathrm{~km}$ south of her capture location (and $88.9 \mathrm{~km}$ south of her last location in Cambridge) in the town of Dartmouth, Massachusetts, near the Rhode Island border. To make that voyage Fog had to have crossed (over or under) six major interstate highways, including route 93 described above.

From 17 May 2004 to 3 April 2005 we monitored a pack of Coyotes ("The Cemetery Pack") in the bordering towns of Everett, Malden, and Revere. Four Coyotes were captured and radio-collared in this pack: one, "Maeve" (\#BN0404), a $14.5 \mathrm{~kg}$ lactating female, captured 17 May 2004, was the breeding female; two, "Jet" (\#BN0403), a $15.9 \mathrm{~kg}$ breeding male, captured by netlauncher on 29 June 2004, was Maeve's mate; three, "Jem" (\#BN0406), a 10.0 kg 4.5-month-old pup, was captured on 26 August 2004; and four, "Cour" (\#BN0405), a $12.3 \mathrm{~kg} 5$-month-old pup, was captured on 15 September 2004. The pack consisted of two to three adults (i.e., one additional uncollared coyote was occasionally sighted in the pack's territory - its status was never determined but it was probably a helper Coyote [Way et al. 2002a] to Jet and Maeve) and four pups (two of which were not collared). The group went from six to seven members to four individuals by mid-winter 2004-2005 when it was presumed that some of the pack members (two of the pups [includ- ing Jem, last successfully located on 11 December 2004] and probably the uncollared adult) dispersed. The group resided almost exclusively in a green area (including some thicker woods) surrounding four large connected cemeteries. The entire area was about $2.5 \mathrm{~km}^{2}$ (J. Way, unpublished data) and aside from inactive railroad tracks (i.e., no trains used them) the pack's territory was surrounded by high-density housing units and/or commercial spaces (malls) on all sides. Two roads transected their range, including a straight east-west road (Fuller Street) in the central part of their territory that connected the two cemeteries that they most frequently used.

Most of the cemeteries were surrounded by fencing consisting of vertical metal bars spaced $10 \mathrm{~cm}$ apart. The narrowness of this space prevented the Coyotes from crossing through the fence at random locations. However, a small corridor connected two cemeteries where a $34 \mathrm{~cm}$ opening occurred at a height of $55 \mathrm{~cm}$ in the south cemetery because of a missing metal post and two bent poles, one on each side. After crossing Fuller Street diagonally for about $15 \mathrm{~m}$ the Coyotes could then go through an open $305 \mathrm{~cm} \times 198 \mathrm{~cm}$ gate (this door was never shut) followed by six steps that lead down into the north cemetery. Besides that crossing, there were two roads (one open to cars, the other gated) approximately $50 \mathrm{~m}$ east of the main corridor that the Coyotes could use (by diagonally crossing Fuller Street) to access either cemetery. There was one other opening $(<20 \mathrm{~cm})$ in the south cemetery fence about $400 \mathrm{~m}$ west of the main corridor that led into a residential neighborhood (after crossing Fuller Street) bordering the west part of the north cemetery. Cour was the only coyote to use the road crossing corridor regularly and Maeve was the only one observed to use the neighborhood crossing corridor.

We radio-tracked the Coyotes six to seven days per week on average and, when tracking them at night (street lights illuminating the area), usually made sightings (range: one to ten sightings per night) from our parked, turned off vehicle of one to five Coyotes together crossing the main corridor (exceptions were during a heavy snowstorm [ca. $60 \mathrm{~cm}$ ] when they did not use the south cemetery at all). They often also crossed the road in daylight during the early morning (06:0008:00). During their first 6 months (i.e., April to October) sightings included some of the pups going under the fence $(17 \mathrm{~cm}$ from fence to dirt) about $1 \mathrm{~m}$ west of the opening in the fence leading to the south cemetery, often during the same crossing (i.e., they were together) as other Coyotes went through the opening in the fence. This section of Fuller Street was straight, thus the Coyotes could see in both locations and we often watched them, especially the adults, standing on a hill in the south cemetery watching traffic and crossing when there were not any cars going by. Except for two instances when the Coyotes were almost hit by cars (the cars had to brake) all crossings were successful. 
Monitoring of this group ended after the non-dispersing members (Maeve, Jet, Cour and one uncollared) were illegally poisoned.

\section{Discussion}

These data indicate that very small areas, if positioned in the right place, can be very important for Coyotes. These micro-corridors gave access to city habitats with few to no trees (along the railroad tracks) and also connected fragmented areas (cemeteries with fences) in already very urban landscapes. While not ideal habitat for Coyotes, these corridors were certainly better than nothing, and echoing the statement of Beier (1995: 235) when discussing Cougar (Puma concolor) dispersal, "any connection between two isolated patches is better than no connection." Managers can use these data for $\geq 3$ purposes: one, to provide better habitat connectivity in already fragmented landscapes (e.g., opening sections of fence where wildlife is likely to cross); two, proactively establishing these types of corridors (ideally larger than described in this paper) where development is planned; and three, more regional planning where important habitat exists and maintaining linkages between separated core habitats.

The importance of sub-marginal habitats can not be overstated to facilitate animal movement. For example, Beier (1995) noted that Cougars can use corridors $100 \mathrm{~m}$ wide if the distance is $<800 \mathrm{~m}$ and $400 \mathrm{~m}$ wide if $1-7 \mathrm{~km}$, yet adult Cougars have enormous home ranges in the hundreds of $\mathrm{km}^{2}$ (Beier 1993, 1995). Likewise, species previously thought to inhabit only wilderness such as Wolves (Canis lupus) can often live at least at the edge of human-dominated areas if not persecuted (Mech and Boitani 2003) and no doubt corridors facilitate travel in and out of these landscapes. While preserving larger areas (e.g., Beier 1995) is preferred, this is not always possible in the real world and it is increasingly being discovered that animals are adaptable and can often respond to human-induced changes (e.g., Mech and Boitani 2003). Therefore, it is imperative to at least link what is remaining of our wild lands and this can start at the very specific microcorridor landscape scale. For example, bridges that exist because of waterways (common in many cities) could also promote wildlife movement if cover and some space are provided.

\section{Acknowledgments}

We thank the Way and Cifuni families, N. Lima, S. Cifuni, E. Strauss, Environmental Studies Program, and Urban Ecology Institute at Boston College, B. Binder and Saugus Animal Hospital, and Revere High School.

\section{Literature Cited}

Beier, P. 1993. Determining minimum habitat areas and habitat corridors for cougars. Conservation Biology 7: 94-108.

Beier, P. 1995. Dispersal of juvenile cougars in fragmented habitat. Journal of Wildlife Management 59: 228-237.

Conner, M. M., M. M. Jaeger, T. J. Weller, and D. R. McCullough. 1998. Effect of coyote removal on sheep depredation in northern California. Journal of Wildlife Management 62: 690-699.

Gilbert, F., A. Gonzalez, and I. Evans-Freke. 1998. Corridors maintain species richness in the fragmented landscapes of a microecosystem. Proceedings of the Royal Society of London 265: 577-582.

Gittleman, J. L., S. M. Funk, D. Macdonald, and R. K. Wayne. Editors. 2001. Carnivore conservation. Cambridge University Press, New York. 675 pages.

Grinder, M. I., and P. R. Krausman. 2001. Home range, habitat use, and nocturnal activity of coyotes in an urban environment. Journal of Wildlife Management 65: 887-898.

Mech, L. D., and L. Boitani. Editors. 2003. Wolves: behavior, ecology, and conservation. University of Chicago Press, Chicago, Illinois. 448 pages.

Meffe, G. K., and C. R. Carroll. 1994. Principles of conservation biology. Sinauer Associates, Sunderland, Massachusetts. 601 pages.

Parker, G. R. 1995. Eastern coyote: the story of its success. Nimbus Publishing, Halifax, Nova Scotia. 254 pages.

Sacks, B. N., K. M. Blejwas, and M. M. Jaeger. 1999. Relative vulnerability of coyotes to removal methods on a northern California ranch. Journal of Wildlife Management 63: 939-949.

Sequin, E. S., M. M. Jaeger, P. F. Brussard, and R. H. Barrett. 2003. Wariness of coyotes to camera traps relative to social status and territorial boundaries. Canadian Journal of Zoology 81: 2015-2025.

Way, J. G., I. M. Ortega, and P. J. Auger. 2002a. Eastern coyote home range, territoriality and sociality on urbanized Cape Cod, Massachusetts. Northeast Wildlife 57: 1-18.

Way, J. G., I. M. Ortega, P. J. Auger, and E. G. Strauss. 2002b. Box-trapping eastern coyotes in southeastern Massachusetts. Wildlife Society Bulletin 30: 695-702.

Way, J. G., I. M. Ortega, and E. G. Strauss. 2004. Movement and activity patterns of eastern coyotes in a coastal, suburban environment. Northeastern Naturalist 11: 237 254.

Received 4 October 2005

Accepted 14 March 2007 